\title{
Randomised comparison of ondansetron and metoclopramide plus dexamethasone for chemotherapy induced emesis
}

\author{
G S Dick, S T Meller, C R Pinkerton
}

\begin{abstract}
The serotonin $\left(5 \mathrm{HT}_{3}\right)$ antagonist ondansetron was compared in a randomised study with metoclopramide and dexamethasone for the prevention of chemotherapy induced emesis. Thirty children aged 1-15 years with acute lymphoblastic leukaemia received 'intensification modules' according to the MRC United Kingdom acute lymphoblastic leukaemia regimen UKALL XI. This contains the moderately emetogenic drugs daunorubicin, etoposide, and cytarabine. Fifteen children received an intravenous loading dose of ondansetron followed by intravenous or oral doses 12 hourly for five days. Fifteen children received intravenous metoclopramide every six hours for three days with a loading dose of dexamethasone, repeated every eight hours for three days intravenously or orally. Efficacy was assessed by a diary card documenting the incidence of nausea, retching, or vomiting. In the 24 hour period after starting chemotherapy, ondansetron was more effective, with a complete or major response rate of $93 \%$, compared with $33 \%$ using metoclopramide/dexamethasone. (Arch Dis Child 1995; 73: 243-245)
\end{abstract}

Keywords: chemotherapy, anti-emetic, leukaemia.

Nausea and vomiting induced by cytotoxic drugs strongly influence a patient's perception of curative chemotherapy. ${ }^{1}$ Until recently this was a major problem in children. It is distressing to both parents and patients and can be the main reason for refusing admission and treatment. ${ }^{2}$ Excessive vomiting also carries the attendant problems of dehydration and electrolyte imbalance, potentiating chemotoxicity and delaying discharge from hospital. Effective antiemetics can prevent hospital admission in some cases. ${ }^{3}$ The widely used combination of metoclopramide and dexamethasone has proved to have limited efficacy with certain types of chemotherapy induced emesis. ${ }^{4}$ In adults, high dose metoclopramide is very effective, ${ }^{5}$ but severe extrapyramidal side effects are a particular problem in children. These range from general restlessness or crying to dystonias (including oculogyric crisis and opisthotonos) and dyskinesia. ${ }^{6-8}$ Serotonin $\left(5 \mathrm{HT}_{3}\right)$ receptor antagonists are devoid of dopamine antagonist activity and therefore do not cause such extrapyramidal reactions. Documented minor side effects include headache, flushing, constipation, and the occasional asymptomatic rise in liver transaminases. ${ }^{9}$ These drugs - ondansetron and granisetron - have been shown to be the antiemetics of first choice in highly emetogenic regimens, such as cisplatin or ifosfamide. ${ }^{1011}$ Because of their cost, however, there has been an understandable reluctance to use them more widely for moderately emetogenic regimens, particularly since their superiority over other combinations has been less clear in adult studies. ${ }^{12}$ In the present study we selected a chemotherapy regimen commonly used in children to document the incidence of vomiting and nausea where our standard antiemetic treatment was given and to determine whether better results could be obtained with ondansetron. The goal was to abolish emesis completely, challenging the assumption that this was not possible without unacceptable toxicity.

\section{Methods}

Thirty patients aged 18 months to 15 years who were undergoing treatment with the UKALL XI intensification chemotherapy regimen entered the study. They received vincristine $1.5 \mathrm{mg} / \mathrm{m}^{2}$ intravenously once, daunorubicin $45 \mathrm{mg} / \mathrm{m}^{2}$ daily twice, etoposide $100 \mathrm{mg} / \mathrm{m}^{2}$ intravenously daily five times, and cytarabine $100 \mathrm{mg} / \mathrm{m}^{2}$ intravenously 12 hourly for five days, with prednisolone $40 \mathrm{mg} / \mathrm{m}^{2}$ daily for seven days orally and thioguanine 80 $\mathrm{mg} / \mathrm{m}^{2}$ daily for five days orally. There were 14 girls and 16 boys in the study.

Written informed consent was obtained from the parents and older children, and the study was approved by the Royal Marsden NHS Trust ethics committee.

Patients were required to meet the following study criteria: they had not experienced uncontrollable nausea and vomiting on previous treatments, and they had no other serious illnesses, no other antiemetic administration, no nausea and vomiting before the treatment was given, no concurrent benzodiazepines, no cerebral metastases or meningeal leukaemia, and no previous hypersensitivity or lack of efficacy with ondansetron or metoclopramide.

A full blood count, electrolyte estimation, creatinine, and liver function tests were performed before treatment. Details of previous chemotherapy courses and episodes of nausea or vomiting were documented.

Of the 30 patients studied, 25 were receiving the early intensification module and of these, seven had previously received daunorubicin 
Table 1 Ondansetron dose (as per Glaxo Study No GLZOF/008, 1991)

\begin{tabular}{llll}
\hline $\begin{array}{l}\text { Surface area } \\
(\mathrm{m} 2)\end{array}$ & $\begin{array}{l}\text { Intravenous dose } \\
\text { (load }+ \text { bd) }\end{array}$ & $\begin{array}{l}\text { Maintenance bd } \\
\text { (iv or } p o \text { ) }\end{array}$ & $\begin{array}{l}\text { Oral dose } \\
\text { (bd) }\end{array}$ \\
\hline$<0.6$ & $3 \mathrm{mg} / \mathrm{m}^{2}$ & $3 \mathrm{mg} / \mathrm{m}^{2}$ or $2 \mathrm{mg}$ & $2 \mathrm{mg}$ \\
$0.6-1.2$ & $3 \mathrm{mg} / \mathrm{m}^{2}$ & $3 \mathrm{mg} / \mathrm{m}^{2}$ or $4 \mathrm{mg}$ & $4 \mathrm{mg}$ \\
$>1.2$ & $8 \mathrm{mg}$ & $8 \mathrm{mg}$ & $8 \mathrm{mg}$
\end{tabular}

$\mathrm{bd}=$ twice daily; iv=intravenously; po= orally.

with their induction module. Five patients were studied during the late intensification module and so had received daunorubicin in their early intensification module; thus 18 patients were naive to daunorubicin and 12 patients had previously received this agent.

The antiemetic treatment was allocated by block balanced coding held in the pharmacy. Patients randomised to ondansetron received an intravenous loading dose of $3-8 \mathrm{mg} / \mathrm{m}^{2}$ over 3-5 minutes before daunorubicin was given at 0 and 24 hours. The 12 hour dose was also given intravenously and then, if tolerated, oral ondansetron was begun 12 hourly at 36 hours for three days (for a total of three intravenous doses and six oral doses). The dose was determined by surface area $\left(\mathrm{m}^{2}\right)$ (table 1$)$.

Patients randomised to metoclopramide/ dexamethasone received intravenous metoclopramide $10 \mathrm{mg} / \mathrm{m}^{2}$ starting before chemotherapy and continuing every six hours for a minimum of three days. Procyclidine $2.5 \mathrm{mg}$ was given routinely intravenously with each dose of metoclopramide to prevent extrapyramidal reactions (table 2). Because of the differences between the antiemetic combinations the study was not blind. The child was, however, unaware of whether 'standard' or 'novel' antiemetics were given.

Patients who failed to achieve antiemetic control (more than two vomits or retches) or experienced severe nausea or adverse events were given alternative treatment. Antiemetic efficacy was assessed by a diary card given to the family/patient which documented the incidence of vomiting and retching, the degree of nausea, general appetite, and any other symptoms (table 3 ). These were evaluated for the initial 24 hours, and then on days 2-6. An emetic episode was defined as a vomit or a retch. Emesis was evaluated and graded as: complete response - no emetic episodes; major response - 1-2 emetic episodes; minor response - 3-5 emetic episodes; failure - more than five emetic episodes. Nausea was graded as: not feeling at all sick, feeling sick, or feeling very sick (=severe nausea).

\section{Results}

During the first 24 hour period after starting chemotherapy 11 patients who received

Table 2 Dose schedules for metoclopramide, dexamethasone, and procyclidine

\begin{tabular}{lcc}
\hline Drug & $\begin{array}{l}\text { Intravenous } \\
\text { dose load }\end{array}$ & Maintenance \\
\hline Metoclopramide & $10 \mathrm{mg} / \mathrm{m}^{2}$ & $10 \mathrm{mg} / \mathrm{m} 2$ iv qds \\
Dexamethasone & $4 \mathrm{mg} / \mathrm{m}^{2}$ & $2 \mathrm{mg} / \mathrm{m} 2$ iv tds or po \\
Procyclidine & $2.5-5 \mathrm{mg}$ & $2.5-5 \mathrm{mg}$ \\
\hline
\end{tabular}

iv=intravenously; $t(q) d s=$ three (four) times daily; po=orally.
Table 3 Diary card

DIARY CARD
Please assess the following:
1. How many times has your child vomited following the
start of chemotherapy?
2. How many times has your child retched (been sick
without bringing anything up) following the start of
chemotherapy?
3. How severe has your child's nausea (sick feeling) been
following on from chemotherapy?
Please grade nausea as follows:
(a) Not feeling sick at all
(b) Feeling sick
(c) Feeling very sick
Please grade your child's appetite as follows:
(a) Better than usual
(b) As usual
(c) Worse than usual
(d) Very poor
(e) No appetite
Have there been any other symptoms which have upset
your child?

ondansetron achieved complete response compared with three patients who received metoclopramide/dexamethasone (table 4). Overall 14 (93\%) of children who received ondansetron achieved complete response or major response, whereas five $(33 \%)$ of children who received metoclopramide/dexamethasone achieved equal efficacy $(p<0.001$ by Mann-Whitney test) (figure). One patient aged 18 months randomised to ondansetron was difficult to assess as he vomited only with coughing. The ondansetron was changed to six hourly in an effort to control the emesis but he continued to vomit when coughing.

Of the 15 children randomised to metoclopramide/dexamethasone 10 were changed to ondansetron during the first 24 hours. All responded to this change. One patient was changed following her second administration of intravenous metoclopramide when she felt very unwell and agitated. A second child was changed because of behaviourial disturbances after each of two doses.

Previous daunorubicin exposure did not appear to affect the results. Five patients randomised to ondansetron and seven patients randomised to received metoclopramide/dexamethasone were previously exposed to daunorubicin. In these patients emesis was well controlled with ondansetron but efficacy was only apparent in one patient who received metoclopramide/dexamethasone.

Delayed emesis or nausea (on days 6-11) occurred in seven patients. Four had initially received ondansetron and three metoclopramide. One had been changed from metoclopramide to ondansetron. In all cases these symptoms were mild.

'Other symptoms' documented were stomach pains in two patients and tiredness in

Table 4 Details of randomisation, early/late intensification, and response to study antiemetic

\begin{tabular}{llllll}
\hline & \multicolumn{3}{l}{ Response } \\
\cline { 2 - 6 } & $C R$ & $M R$ & $N$ & $F$ \\
\hline $\begin{array}{l}\text { Ondansetron }(\mathrm{n}=15) \\
\quad \text { Early intensification }(\mathrm{n}=13)\end{array}$ & 9 & 3 & 1 & \\
$\quad \begin{array}{l}\text { Late intensification }(\mathrm{n}=2) \\
\text { Metoclopramide +dexamethasone } \\
\quad \text { Early intensification }(\mathrm{n}=12)\end{array}$ & 2 & & & \\
$\quad$ Late intensification $(\mathrm{n}=3)$ & 3 & 2 & 4 & 3 \\
\hline
\end{tabular}

$\mathrm{CR}=$ complete response; $\mathrm{MR}=$ major response; $\mathrm{N}=$ minor response; $\mathrm{F}=$ no response. 


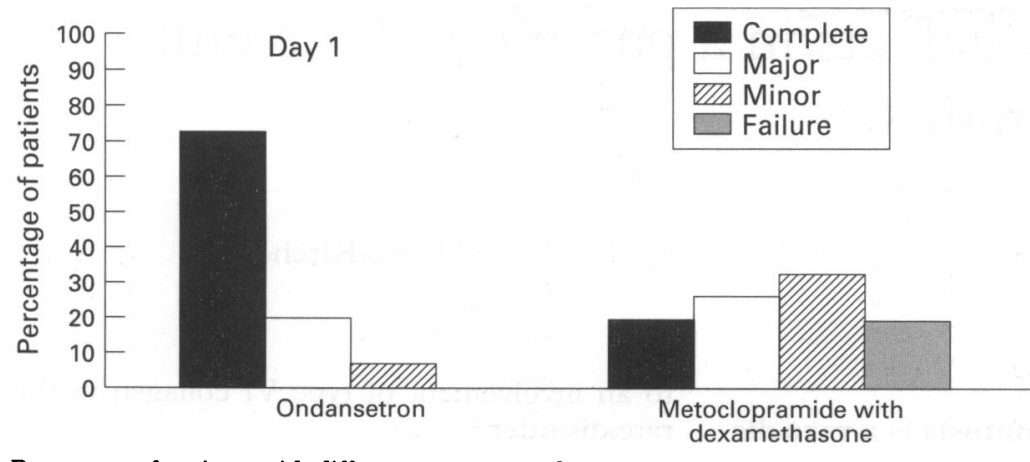

Percentage of patients with different response grades.

one patient receiving metoclopramide/dexamethasone, and leg pains in one patient receiving ondansetron.

The appetite grading was consistent with the overall results of the study. Of the patients randomised to ondansetron, $90 \%$ recorded 'as usual' or 'better than usual', whereas of the patients randomised to metoclopramide/ dexamethasone, $87 \%$ recorded either 'worse than usual' or 'very poor'.

\section{Discussion}

This study shows that ondansetron given as an initial dose followed by 12 hourly intravenous and/or oral dosing is sufficient to achieve $93 \%$ efficacy in controlling emesis induced by combination chemotherapy in patients receiving treatment for acute lymphoblastic leukaemia.

Since daunorubicin was excluded from the UKALL XI induction regimen, patients do not usually experience vomiting during this initial phase of treatment. With the use of ondansetron it should now be possible for the majority of these children to complete their chemotherapy protocol with complete or major control of emesis. This would make admission to hospital less traumatic and the whole concept of leukaemia treatment less daunting for parents.

Financial restraints in the present economic climate may influence or restrain the use of certain drugs and the more effective agents may be limited to regimens regarded as 'highly' emetogenic. While all of the $5 \mathrm{HT}_{3}$ antagonists are certainly expensive they are probably costeffective.

On the study schedule described, ondansetron is given twice a day, whereas metoclopramide and procyclidine are given four times a day and dexamethasone three times a day. If these agents are given intravenously the cost of disposable equipment must be accounted for, as well as the potential costs and nursing time imposed by the vomiting patient. Moreover, our current practice is to start with a single daily dose of ondansetron during chemotherapy and increase to 12 hourly only if the single dose is ineffectve.

Access to a vein, by either a Hickman line, a central line, or a cannula, is a potential infection risk and is distressing to some children. Therefore, if an intravenous route has been chosen for antiemetic administration, the less such access is required the greater the potential benefit for the patient. Administration of metoclopramide with dexamethasone requires access on possibly six occasions each day, whereas ondansetron requires access only twice.

In adult studies $5 \mathrm{HT}_{3}$ antagonists have shown benefit with the more emetogenic (cisplatin based) regimens and they are therefore often reserved for second line use after failure of other antiemetics. Anticipatory vomiting develops readily in children and is very difficult to treat; therefore it is important to obtain antiemetic control in the initial stages. ${ }^{13}$ The number of patients recruited to this study was small but the marked difference in efficacy in a regimen classified as moderately emetogenic is significant.

With the advent of $5 \mathrm{HT}_{3}$ antagonists, particularly in combination with dexamethasone, ${ }^{14}$ it is no longer acceptable for children to be lethargic, unwell with nausea and vomiting, or at risk from extrapyramidal reactions when receiving treatment for leukaemia. The optimal route and schedule for ondansetron and the other $5 \mathrm{HT}_{3}$ antagonists remains to be determined in children and it is likely that shorter simpler schedules than used in this study may prove equally effective.

We are grateful to Joan Malings for helping to prepare the manuscript, Sue Ashley for statistical advice, and Glaxo UK for assistance in the planning and execution of the study.

1 Coates A, Abraham S, Kaye SB, et al. On the receiving end - patient perception of the side-effects of cancer chemotherapy. Eur f Cancer Clin Oncol 1983; 19: 203-8.

2 Frick SB, Guzzi DelPo E, Keith JA, Davis MS. Chemotherapy-associated nausea and vomiting in pediatric oncology patients. Cancer Nursing 1988; 11:

3 Pinkerton CR, Williams D, Wootton C, Meller ST, McElwain TJ. 5-HT 3 antagonist ondansetron - an effective outpatient antiemetic in cancer treatment. Arch Dis Child 1990; 65: 822-5.

4 Cunningham D, Bradley CJ, Forrest GJ, et al. A randomized trial of oral nabilone and prochlorperazine compared to intravenous metoclopramide and dexamethasone in the treatment of nausea and vomiting induced by chemotherapy regimens containing cisplatin or cisplatin analogues. Eur f Cancer Clin Oncol 1988; 24: 685-9.

5 Gralla RJ, Itri LM, Pisko SE, et al. Antiemetic efficacy of high-dose metoclopramide: randomized trials with placebo and prochlorperazine in patients with chemotherapy-induced nausea and vomiting. $N$ with f Med 1981; 305: 905-9.

6 Bateman DN, Rawlins MD, Simpson JM. Extrapyramidal reactions with metoclopramide. BMF 1985; 291 : 930-2

7 Terrin BN, McWilliams NB, Maurer HM. Side effects of metoclopramide as an antiemetic in childhood cancer metoclopramide as an antiemetic in childhoc

8 Allen JC, Gralla R, Reilly L, Kellick M, Young C. Metoclopramide: dose-related toxicity and preliminary antiemetic studies in children receiving cancer chemotherapy. F Clin Oncol 1985; 3: 1136-41.

9 Stevens RF. The role of ondansetron in paediatric patients: a review of three studies. Eur $\mathcal{f}$ Cancer 1991; 27: S20-2.

10 Lemerle J, Amaral D, Southall DP, Upward J, Murdoch $\mathrm{RD}$. Efficacy and safety of granisetron in the prevention of chemotherapy-induced emesis in paediatric patients. Eur $\mathcal{F}$ Cancer 1991; 27: 1081-3.

11 Marty M, Droz JP, Pouillart P, Paule B, Brion N, Bons J. GR38032F, a $5 \mathrm{HT}_{3}$ receptor antagonist, in the prophylaxis of acute cisplatin-induced nausea and vomiting. Cancer Chemother Pharmacol 1989; 23: 389-91.

12 Jones AL, Hill AS, Soukop M, et al. Comparison of dexa methasone and ondansetron in the prophylaxis of dexamethasone and ondansetron in the prophylaxis of emesis 1991; 338: 483-7. Banks $C$; 1 : 483-7.

1991;. Alleviating anticipatory vomiting. Nursing Times

14 Cunningham D, Turner A, Hawthorn J, Rosin RD. Ondansetron with and without dexamethasone to treat chemotherapy-induced emesis. Lancet 1989; ii: 1323. 